\title{
What Makes a Good Physics Lab Partner?
}

\author{
Danny Doucette, Russell Clark, and Chandralekha Singh \\ Department of Physics and Astronomy, University of Pittsburgh, Pittsburgh, PA, USA 15260
}

Students who take lab courses engage in active, collaborative learning that has the potential to teach scientific thinking skills while also stimulating students' interest in science and developing their self-efficacy. We describe different types of collaboration in terms of the mutuality of engagement they represent, and investigate how these different types of collaboration impacted student interest and self-efficacy in introductory physics labs. We surveyed college physics students about their beliefs and experiences regarding working with a lab partner. We find that when asked explicitly about what they valued in a lab partner, a majority of students noted that they wanted a "fair split" of the work. However, we find that students experienced improved physics interest and self-efficacy when they participated equally in all aspects of the lab, such as operating the apparatus and recording the data, which is a different form of mutuality of engagement. This form of participation disproportionately benefited women, a traditionally disadvantaged group in physics labs. Our findings suggest that students' physics interest and self-efficacy might be positively impacted in lab courses that are designed to ensure that students participate equally in all aspects of the lab work, as opposed to lab courses in which students split up their work inequitably, as they might prefer to do.

\footnotetext{
2020 PERC Proceedings edited by Wolf, Bennett, and Frank; Peer-reviewed, doi.org/10.1119/perc.2020.pr.Doucette Published by the American Association of Physics Teachers under a Creative Commons Attribution 4.0 license. Further distribution must maintain the cover page and attribution to the article's authors.
} 


\section{INTRODUCTION AND FRAMEWORK}

The introductory physics lab brings together students to collaborate actively in scientific meaning-making [1-11]. While evidence-based collaborative and active learning may improve student outcomes on average, the impact of these pedagogical strategies on diverse pools of students may not be uniformly positive [12-14].

In order to understand how collaboration in a primarily traditional introductory physics lab can impact a student's identity trajectory $[13,15,16]$, we investigated the ways in which interactions with lab partners affected students' interest and self-efficacy in an introductory physics course. We approached the problem in three ways: first, by asking students about the characteristics of an ideal lab partner; second, by investigating how students' perceptions of the distribution of the lab work between the partners (equal or unequal participation in all aspects of the lab) is related to self-reported changes in their interest and self-efficacy in physics; and third, by assessing whether gender might play a role in the relationship between lab work distribution and self-efficacy. This quantitative work is designed to complement qualitative analysis reported elsewhere [17].

In order to contextualize our research, we adopted a framework based on identity in communities of practice that has been used before in physics education research [18-20]. A community of practice consists of three elements: the domain, the community, and the practice [21]. For our context, the domain consists of student learning in the introductory physics lab, the community is the pair (or sometimes triplet) of students who collaborate each week on their lab work, and the practice is a 3-hour guided inquiry lab investigation that the students undertake together [22]. In a community of practice framework, students develop their domain-related identity (i.e., their physics identity, or the "type of person" they see themselves as [15]) within a community of practice through engaged participation [21] in relevant activities. In the case of the introductory physics lab, we focused on how students' interactions with their partner(s) affected the development of their physics identity as they conducted experiments and analyzed their results.

One aspect of the process of identity development is 'mutuality of engagement,' a type of competence in which students develop the ability to engage with other members of their community and to establish relationships around their practice rooted in mutual and community benefit [18, 23]. As students do their lab work together (engagement), how do they interact productively, give and receive help, and coordinate the boundaries of their cooperative work? As a relevant example, consider two different ways that pairs of students could split their lab work equally. In partnership A, one student does all the writing while their partner sets up the apparatus and makes the measurements. In this case, if each task takes $50 \%$ of the time and effort then the students might view their mutuality of engagement as fair. However, this mutuality of engagement is not equitable because the students do not have equal opportunities to benefit from the various lab learning experiences, such as operating the apparatus and recording and analyzing the data. By way of contrast, in partnership B two students share the work equally: they each get opportunities to carry out all the aspects of the lab, including manipulating the equipment and recording and analyzing the data. In this case, the mutuality of engagement is more equitable.

In this investigation, we focused on two facets of identity development that were assessed using survey data: physics interest and self-efficacy. Physics interest has been associated with both course and career decisions [16]. Self-efficacy (sometimes also called competency belief) relates to a student's belief in their ability to succeed in a certain situation, task, or domain [24], and has been associated with student performance and persistence $[25,26]$. Both physics interest and self-efficacy have been shown to impact students' identity development in physics [27, 28]. In this research, we investigated how the nature of a lab-group's mutuality of engagement might have affected the development of students' interest in physics and their self-efficacy.

\section{METHODOLOGY}

Participants in this research study were students enrolled in a one-semester introductory physics lab course at a large state-related research university in the USA. These students included physical science and health science majors, but not engineering students who take a different lab course. For three semesters, data was collected via bubble sheets filled out at the end of the lab period, and for the most recent semester the survey was filled out online. Since students received bonus points for completing the survey, the response rate was more than $90 \%$ for all four semesters, including the most recent.

In the lab, students worked in pairs (or triplets, if necessary) to complete a 3-hour course of lab work each week. Student partnerships were self-selected and appeared to be mostly random, as students typically worked with whomever they sat beside at the start of the first lab session of the semester. Pre-lab and homework assignments were completed individually, but a small amount of collaboration was typically required outside of the lab to complete and submit the digital lab report. Lab partnerships were stable through the semester and received the same grade for their lab reports.

What Do Students Want? In the first part of the investigation, students were asked to respond to the prompt, "In the space below, please describe the characteristics of an ideal lab partner." We collected data from 120 students during two semesters for this part of the investigation. Responses were read and a generative coding scheme [29] was developed to categorize the responses. Two researchers independently categorized the first 49 responses in order to assess the reliability of the coding scheme and categorization process, producing a Cohen's $\kappa=0.75$ which indicates 'excellent' agreement [30]. 
An Even Split or an Equitable Distribution? As outlined in the introduction, there may be a difference between students splitting their work evenly (e.g., partnership A) and dividing the work so that all students get to participate equally in all aspects of the lab, including both work with the apparatus and recording and analyzing data (e.g., partnership B). In order to investigate whether students benefit from participating equally in all aspects of the lab, for the second part of the investigation we collected three semesters' of data from 163 men and 258 women to questions pertaining to peer effect on interest. We also analyzed responses from 300 men and 492 women pertaining to peer effect on self-efficacy on an endof-semester survey in the lab, including a fourth semester of data in order to increase the sensitivity of our analysis. These survey questions were validated along with other constructs on a larger motivational survey using think-aloud individual interviews with students to ensure that students interpreted the questions correctly, factor analysis of student responses to ensure that the questions grouped into clusters as expected, as well as analysis of Cronbach's alpha for each factor and Pearson correlation amongst different factors [31]. In order to investigate how equal participation predicts peer effect on physics interest or peer effect on physics self-efficacy in a multiple linear regression model, we used gender and a selfefficacy construct extracted from E-CLASS $[32,33]$ as controls to improve the explanatory power of the model. We note that the larger pool of data (300 men and 492 women) for how equal participation predicts peer effect on self-efficacy allowed smaller effects to manifest as statistically significant if they were present.

We obtained gender information by connecting student responses with anonymized institutional records of students' genders, which were self-reported as Male or Female at the time of application to our university. While we recognize that gender is not a binary construct, other gender identities were not included in this institutional data and all students included in this study selected one of these options.

The set of questions on the survey related to the effect of peer interactions on the participant's interest and self-efficacy in physics is shown in Table I. We hypothesized that changes in a student's interest and self-efficacy in physics might depend on the nature of the group's mutuality of engagement, and specifically on whether students participated equally in all aspects of the lab, which we assessed by querying whether the survey taker and their partner "participated equally in each component of the lab which includes: (i) manipulating the equipment and (ii) data analysis" on a 5-point Lickert scale from "Strongly Disagree" to "Strongly Agree".

As noted earlier, we also analyzed responses to the ECLASS survey [32], which students completed at the start and end of the semester, in order to control for students' selfefficacy in our linear regression models. We extracted a subset of four items from the E-CLASS that are related to the participants' own perceptions of their self-efficacy [33], shown in Table I.

Finally, before carrying out the multiple linear regressions,
TABLE I. Validated survey items related to the E-CLASS selfefficacy, peer effects on physics interest, and peer effects on selfefficacy constructs

\section{Self-Efficacy ECLASS items}

If I wanted to, I think I could be good at doing research.

When I approach a new piece of lab equipment, I feel confident I can learn how to use it well enough for my purposes.

If I try hard enough I can succeed at doing physics experiments.

Nearly all students are capable of doing a physics experiment if they work at it.

\section{Peer effect on physics interest items}

My experiences and interactions with other students in this class

... stimulated my enthusiasm for physics.

... made me enjoy physics more.

... increased my interest in physics.

Peer effect on self-efficacy items

My experiences and interactions with other students in this class

... made me feel more relaxed about learning physics.

... increased my confidence in my ability to do physics.

... increased my confidence that I can succeed in physics.

... increased my confidence in my ability to handle difficult physics problems.

for the E-CLASS self-efficacy, the peer effect on physics interest, and the peer effect on physics self-efficacy constructs, we followed established practices for these survey items by collapsing 5-point Lickert scale items to a 3-point scale (i.e., "Strongly Disagree" and "Disagree" were combined, as were "Strongly Agree" and "Agree") [32, 34]. Scores for these three constructs were constructed by assigning +1 for agreement with each item, -1 for disagreement, and 0 for neutral, and then averaging over all the items in each construct. The gender variable was assigned as $0=$ male, $1=$ female. All factors other than gender were normalized to have a mean of 0 and a standard deviations of 1 so that regression correlations are reported in terms of standard deviations [35].

\section{RESULTS}

What Do Students Want? The results of the categorization of student responses to the prompt asking for characteristics of an 'ideal lab partner' are reported in Table II. Since a single response could include several characteristics of an ideal lab partner, the total number of occurrences of different characteristics exceeds the number of responses categorized.

The most frequently cited characteristic for the 'ideal lab partner', reported by more than half of the students, was a willingness to split the work evenly. Responses coded for "fair split" included those that expressed a desire for a 50/50 split, a partner willing to do half the work, or a partner willing to "do their share." These responses reflect a mutuality of engagement that may not be equitable and that may not provide the benefit of equal engagement in all aspects of the lab to all students, as illustrated by example partnership A in the 
TABLE II. Characteristics of an ideal lab partner, according to students. Each response may have included multiple characteristics.

\begin{tabular}{lc}
\hline \hline Characteristic & Occurrences \\
\hline Fair Split & 62 \\
Smart, Knowledgeable & 31 \\
Easygoing, Sympathetic & 28 \\
Hardworking & 27 \\
Communicates & 27 \\
Prepared & 22 \\
Friendly, Kind & 21 \\
Helpful & 18 \\
Enthusiastic, Cheerful & 18 \\
Efficient, Timely & 18 \\
Contributes to my Learning & 14 \\
Intellectually curious & 8 \\
Serious & 3 \\
\hline Total number of responses & 120 \\
\hline \hline
\end{tabular}

introduction. Doing half the work is a relatively simple form of mutuality of engagement in comparison with the advanced levels of cooperation, relationship-building, and mutual benefit that are possible when people collaborate equitably and effectively. In the 120 responses, not one described an ideal lab partner as someone who supported equally sharing each aspect of the work, as in example partnership B.

Personality traits that allow students to easily cooperate and get along well with their partners, such as being easygoing, communicative, friendly and enthusiastic, were frequently cited as being desirable. Another class of characteristics frequently cited were those that might help students complete their lab work efficiently, such as having a partner who is knowledgeable, hardworking, helpful, and timely. Notably uncommon among the responses were characteristics that might be associated with improving one's learning in the lab, such as the partner being intellectually curious or the partner contributing to one's learning.

An Even Split or an Equitable Distribution? We hypothesized a multiple linear regression model,

$$
\begin{aligned}
\hat{y}_{1} & =\hat{\beta}_{0}+\hat{\beta}_{1} x_{1}+\hat{\beta}_{2} x_{2}+\hat{\beta}_{3} x_{3} \\
& +\hat{\beta}_{12} x_{1} x_{2}+\hat{\beta}_{13} x_{1} x_{3}+\hat{\beta}_{23} x_{2} x_{3}
\end{aligned}
$$

to account for how students' responses to the equal participation prompt $\left(x_{1}\right)$ predict their responses to the peer effect on physics interest construct $\left(y_{1}\right)$, using the E-CLASS selfefficacy $\left(x_{2}\right)$ and gender $\left(x_{3}\right)$ as controls. The model also included all two-way interactions between the three independent variables $\left(x_{1}, x_{2}\right.$ and $\left.x_{3}\right)$. In the model, hats denote predicted (or expected) values determined by an ordinary least squares fit in the regression [35].

The multiple linear regression was carried out using an ordinary least squares linear regression algorithm in $\mathrm{R} \mathrm{[36].} \mathrm{The}$ results (see Table III) support the hypothesis of a relationship between participants' likelihood of saying they participated equally in the lab work and their likelihood of reporting that interactions with other students improved their physics interest, with a 0.16 (0.06 to 0.26 at $95 \%$ confidence [35]) standard deviation increase to the peer effect on physics interest for each 1 standard deviation increase in equal participation. Gender was a significant predictor of physics interest, with women on average reporting a value for the peer effect on their physics interest that was 0.31 ( 0.13 to 0.49 at $95 \%$ confidence) standard deviations lower than for men. Likewise, the self-efficacy construct from E-CLASS served as a useful control. No interactions were significant (at $p<0.05$ [35]), thus interactions were removed from the model and are not shown. The model accounted for $11 \%$ of the variance in the outcome variable, as calculated using the adjusted $R^{2}$ [35].

TABLE III. Results from a multiple linear regression model focusing on how equal participation predicts peer effect on physics interest controlling for E-CLASS self-efficacy and gender. $\beta$ denotes standardized regression coefficients and SE is the standard error.

\begin{tabular}{lcc}
\hline \hline Peer Effect on Physics Interest & $\beta$ & $\mathrm{SE}$ \\
\hline Equal Participation & $0.16^{* * *}$ & 0.05 \\
E-CLASS Self-Efficacy & $0.23 * * *$ & 0.05 \\
Gender & $-0.31 * *$ & 0.09 \\
\hline Adjusted R-squared & 0.11 \\
Sample Size & 421 \\
\hline \multicolumn{2}{c}{$* * \mathrm{p}<0.001, * * \mathrm{p}<0.01, * \mathrm{p}<0.05$} \\
\hline
\end{tabular}

We also hypothesized an analogous multiple linear regression model which focuses on how students' responses to the equal participation survey question predict their responses to the peer effect on self efficacy construct using E-CLASS selfefficacy and gender as controls. This model has the same form as the previous one (Equation 1), with the peer effect on self efficacy $\left(y_{2}\right)$ replacing the peer effect on physics interest $\left(y_{1}\right)$ as the outcome variable. As in the previous model, all two-way interactions were included.

The linear regression analysis, reported in Table IV, was performed in the same way as the regression in which the outcome variable was peer effect on physics interest. Nonsignificant $(p>0.05)$ interactions were removed iteratively and are not shown. This model accounted for $16 \%$ of the variation in the outcome variable and included a statistically significant interaction between gender and equal participation, while both gender and equal participation individually were not significant predictors of peer effect on physics selfefficacy. An increase in equal participation predicted no change to the peer effect on self-efficacy for men, with a non-significant 0.02 ( -0.03 to 0.07 at $95 \%$ confidence) regression coefficient. However, the story for women is quite different. Using values from Table IV, women reported a $(0.02+0.17=) 0.19(0.10$ to 0.28 at $95 \%$ confidence $)$ standard deviation increase to the peer effect on physics selfefficacy for each 1 standard deviation increase to equal participation.

These results may also be understood graphically, as de- 
TABLE IV. Results from a linear model focusing on how equal participation predicts peer effect on physics self-efficacy controlling for E-CLASS self-efficacy and gender.

\begin{tabular}{llc}
\hline \hline Peer Effect on Self-Efficacy & \multicolumn{1}{c}{$\beta$} & $(\mathrm{SE})$ \\
\hline Equal Participation & 0.02 & $(0.05)$ \\
E-CLASS Self-Efficacy & $0.34 * * *$ & $(0.03)$ \\
Gender & -0.11 & $(0.07)$ \\
Gender $\times$ Equal Participation & $0.17 *$ & $(0.07)$ \\
\hline Adjusted R-squared & \multicolumn{2}{c}{0.16} \\
Sample Size & \multicolumn{2}{c}{792} \\
\hline \multicolumn{2}{l}{$* * * \mathrm{p}<0.001, * * \mathrm{p}<0.01, * \mathrm{p}<0.05$} \\
\hline \hline
\end{tabular}

picted in Fig. 1. For men, variation in their response to the equal participation question did not significantly affect the outcome (i.e., in Fig. 1 the slope for men is nearly horizontal). However, for women, there is a significant effect: response to the equal participation question is positively associated with the peer impact on self-efficacy (i.e., the slope for women in Fig. 1 is both positive and significantly different from the slope for men). Thus, we can conclude that men who participated equally were not more likely to report that collaboration improved their self-efficacy, but women who participated equally did report a boost to their self-efficacy because of peer interactions.

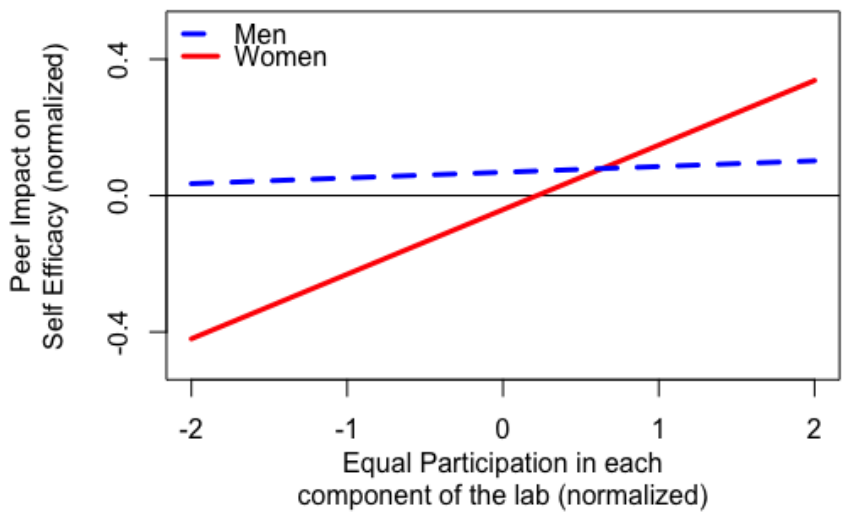

FIG. 1. Linear analysis indicates that male students' perception of the impact of peer interactions on their self efficacy is not associated with whether they participated equally in each component of the lab work (a nearly horizontal slope), while female students' interactions do indicate a significant association between these two factors (a significantly different slope). Horizontal and vertical axes indicate question responses in normalized ( $\mu=0, \sigma=1)$ units.

\section{DISCUSSION AND IMPLICATIONS}

In the first part of the investigation, we saw that students focused on issues of social interaction and work completion when queried about their views of what makes an "ideal lab partner". They wanted a lab partner they could get along with, and who would help them to complete the work. Most importantly, though, they wanted a lab partner who would be willing to do their "fair share": $50 \%$ of the work.

While a 50/50 split might sound equitable on the surface, as reported by previous work [17, 37-40], more so than in samegender groups it is not uncommon for students in mixedgender lab groups to engage in gendered task division in which men tend to do one type of work while women tend to do another. Thus, the mutuality of engagement associated with a "fair split" of the work is markedly different from, and may be less equitable than, the mutuality of engagement associated with an distribution of the learning activities in which each group member participates equally in all aspects of the work. It is not just the amount of work that partners must share, but the types of work as well.

The difference between these two forms of mutuality of engagement is shown to be relevant in the second part of the investigation, in which we found evidence that higher mutuality of engagement was associated with improved physics interest. In particular, students in groups in which each partner "participates equally in all aspects of the lab, including operating the apparatus and recording and analyzing data" (the equal participation variable), on average, reported an increase in their interest in physics. Given the positive outcomes associated with improved physics interest [16], this analysis suggests that instructors should ensure that students experience equal participation in all aspects of their lab work, and not be satisfied with students merely splitting their work 50/50.

The third part of the analysis focused on how equal participation predicted peer effect on self-efficacy controlling for E-CLASS self-efficacy and gender. We showed that men saw no added benefit when they participated equally in all the different aspects of the lab, including data collection and analysis, but that women did experience such a benefit. Given that women currently experience a variety of disadvantages in physics learning environments, including the masculine culture of physics [41] and stereotype threat [42], we suggest that ensuring equal participation in all aspects of lab work can help to improve equity in physics labs by elevating the self-efficacy of women without negatively affecting the selfefficacy of their male classmates.

These results suggest that student learning in introductory physics labs that includes a higher mutuality of engagement is likely to be accompanied by higher average levels of physics interest for all students, and by improved physics self-efficacy for women. In turn, development of interest and self-efficacy may lead to improved physics identity and other related short and long term professional outcomes, especially for women. For this reason, we suggest that instructors who wish to address inequities in their physics labs should seek to ensure that students are able to participate equally in all aspects of the lab work, including operating the apparatus and recording and analyzing data. Returning to the titular question, we conclude that a good lab partner is someone who will not just split up the work, but who will share equally in all aspects of learning in the introductory physics lab. 
[1] E. M. Smith, M. M. Stein, C. Walsh, and N. G. Holmes, Direct measurement of the impact of teaching experimentation in physics labs, Phys. Rev. X 10, 011029 (2020).

[2] B. R. Wilcox and H. J. Lewandowski, Open-ended versus guided laboratory activities: Impact on students' beliefs about experimental physics, Phys. Rev. Phys. Educ. Res. 12, 020132 (2016).

[3] K. Koenig, K. E. Wood, L. J. Bortner, and L. Bao, Modifying traditional labs to target scientific reasoning, J. of Coll. Sci. Teach. 48, 28 (2019).

[4] D. R. Dounas-Frazer, J. T. Stanley, and H. J. Lewandowski, Student ownership of projects in an upper-division optics laboratory course: A multiple case study of successful experiences, Phys. Rev. Phys. Educ. Res. 13, 020136 (2017).

[5] D. Hu and B. M. Zwickl, Examining students' views about validity of experiments: From introductory to Ph.D. students, Phys. Rev. Phys. Educ. Res. 14, 010121 (2018).

[6] E. Etkina and A. V. Heuvelen, Investigative science learning environment - a science process approach to learning physics, in Research-Based Reform of University Physics, Vol. 1 (2007).

[7] E. Brewe, Modeling theory applied: Modeling instruction in introductory physics, Am. J. Phys. 76, 1155 (2008).

[8] K. Ansell and M. Selen, Student attitudes in a new hybrid design-based introductory physics laboratory, in Physics Education Research Conference 2016 (Sacramento, CA, 2016) pp. 36-39.

[9] S. Allie, M. N. Armien, N. Burgoyne, J. M. Case, B. I. CollierReed, T. S. Craig, A. Deacon, D. M. Fraser, Z. Geyer, C. Jacobs, J. Jawitz, B. Kloot, L. Kotta, G. Langdon, K. le Roux, D. Marshall, D. Mogashana, C. Shaw, G. Sheridan, and N. Wolmarans, Learning as acquiring a discursive identity through participation in a community: Improving student learning in engineering education, Eur. J. Eng. Educ. 34, 359 (2009).

[10] M. D. Sharma, A. Mendez, I. M. Sefton, and J. Khachan, Student evaluation of research projects in a first-year physics laboratory, Eur. J. Phys. 35, 025004 (2014).

[11] G. L. Cochran and M. S. Sabella, Understanding and encouraging effective collaboration in introductory physics courses, in AIP Conference Proceedings, Vol. 1064 (AIP, 2008) pp. 95-98.

[12] K. Rosa and F. M. Mensah, Educational pathways of black women physicists: Stories of experiencing and overcoming obstacles in life, Phys. Rev. Phys. Educ. Res. 12, 020113 (2016).

[13] H. B. Carlone and A. Johnson, Understanding the science experiences of successful women of color: Science identity as an analytic lens, J. Res. Sci. Teach. 44, 1187 (2007).

[14] A. Maries, N. I. Karim, and C. Singh, Is agreeing with a gender stereotype correlated with the performance of female students in introductory physics?, Phys. Rev. Phys. Educ. Res. 14, 020119 (2018).

[15] J. P. Gee, Identity as an analytic lens for research in education, Rev. Res. Educ. 25, 99 (2000).

[16] Z. Hazari, G. Sonnert, P. M. Sadler, and M.-C. Shanahan, Connecting high school physics experiences, outcome expectations, physics identity, and physics career choice: A gender study, J. Res. Sci. Teach. 47, 978 (2010).

[17] D. Doucette, R. Clark, and C. Singh, Hermione and the secretary: how gendered task division in introductory physics labs can disrupt equitable learning, Eur. J. Phys. 41, 035702 (2020).
[18] I. Rodriguez, R. M. Goertzen, E. Brewe, and L. H. Kramer, Developing a physics expert identity in a biophysics research group, Phys. Rev. ST Phys. Educ. Res. 11, 010116 (2015).

[19] P. W. Irving and E. C. Sayre, Conditions for building a community of practice in an advanced physics laboratory, Phys. Rev. ST Phys. Educ. Res. 10, 010109 (2014).

[20] E. W. Close, J. Conn, and H. G. Close, Becoming physics people: Development of integrated physics identity through the learning assistant experience, Phys. Rev. Phys. Educ. Res. 12, 010109 (2016).

[21] E. Wenger, Communities of Practice: Learning, Meaning, and Identity (Cambridge University Press, 1999).

[22] D. R. Sokoloff, P. W. Laws, and R. K. Thornton, RealTime Physics: Active learning labs transforming the introductory laboratory, Eur. J. Phys. 28, S83 (2007).

[23] E. Wenger, Communities of practice and social learning systems, Organization 7, 225 (2000).

[24] A. Bandura, Self-efficacy mechanism in human agency, Am. Psychol. 37, 122 (1982).

[25] V. Sawtelle, E. Brewe, and L. H. Kramer, Exploring the relationship between self-efficacy and retention in introductory physics, J. Res. Sci. Teach. 49, 1096 (2012).

[26] E. M. Marshman, Z. Y. Kalender, T. Nokes-Malach, C. Schunn, and C. Singh, Female students with A's have similar physics self-efficacy as male students with C's in introductory courses: A cause for alarm?, Phys. Rev. Phys. Educ. Res. 14, 020123 (2018).

[27] A. Godwin, G. Potvin, Z. Hazari, and R. Lock, Identity, critical agency, and engineering: An affective model for predicting engineering as a career choice, J. Eng. Educ. 105, 312 (2016).

[28] Z. Y. Kalender, E. Marshman, C. D. Schunn, T. J. NokesMalach, and C. Singh, Why female science, technology, engineering, and mathematics majors do not identify with physics: They do not think others see them that way, Phys. Rev. Phys. Educ. Res. 15, 020148 (2019).

[29] V. K. Otero and D. B. Harlow, Getting started in qualitative physics education research, Reviews in PER Vol 2, 1 (2009).

[30] J. L. Fleiss, B. Levin, and M. C. Paik, Statistical Methods for Rates and Proportions (John Wiley \& Sons, 2013).

[31] K. Whitcomb and C. Singh, Recognition always matters: A cross-sectional study of the physics identity of physics majors, European Journal of Physics (in preparation).

[32] B. Wilcox and H. Lewandowski, Students' epistemologies about experimental physics: Validating the Colorado Learning Attitudes about Science Survey for experimental physics, Phys. Rev. Phys. Educ. Res. 12, 010123 (2016).

[33] D. Doucette, R. Clark, and C. Singh, What's happening in traditional and inquiry-based introductory labs? An integrative analysis at a large research university, in Physics Education Research Conference 2018 (Washington, DC, 2018).

[34] D. Hu, B. M. Zwickl, B. R. Wilcox, and H. J. Lewandowski, Qualitative investigation of students' views about experimental physics, Phys. Rev. Phys. Educ. Res. 13, 020134 (2017).

[35] J. Cohen, Statistical Power Analysis for the Behavioral Sciences (Academic Press, 2013).

[36] R Core Team, R: A Language and Environment for Statistical Computing, R Foundation for Statistical Computing, Vienna, Austria (2013).

[37] N. Holmes, I. Roll, and D. Bonn, Participating in the physics 
lab: Does gender matter?, Physics in Canada, Special Issue on Physics Education Research 70, 84 (2014).

[38] K. N. Quinn, K. L. McGill, M. M. Kelley, E. M. Smith, and N. Holmes, Who does what now? How physics lab instruction impacts student behaviors, in Physics Education Research Conference 2018 (Washington, DC, 2018).

[39] K. N. Quinn, M. M. Kelley, K. L. McGill, E. M. Smith, Z. Whipps, and N. G. Holmes, Group roles in unstructured labs show inequitable gender divide, Phys. Rev. Phys. Educ. Res.
16, 010129 (2020).

[40] A. T. Danielsson and C. Linder, Learning in physics by doing laboratory work: Towards a new conceptual framework, Gend. Educ. 21, 129 (2009).

[41] A. J. Gonsalves, A. Danielsson, and H. Pettersson, Masculinities and experimental practices in physics: The view from three case studies, Phys. Rev. Phys. Educ. Res. 12, 020120 (2016).

[42] G. C. Marchand and G. Taasoobshirazi, Stereotype threat and women's performance in physics, International Journal of Science Education 35, 3050 (2013). 